\title{
Fms/Trk Tyrosine Kinase Inhibitor PLX7486 Tosylate
}

National Cancer Institute

\section{Source}

National Cancer Institute. Fms/Trk Tyrosine Kinase Inhibitor PLX7486 Tosylate. NCI

Thesaurus. Code C105804.

The tosylate salt form of PLX7486, a selective inhibitor of the receptor tyrosine kinases colony-stimulating factor-1 receptor (CSF1R; fms) and neurotrophic tyrosine kinase receptor types 1, 2 and 3 (TrkA, TrkB, and TrkC, respectively) with potential antineoplastic activity. Upon administration, PLX7486 binds to and inhibits the activity of these tyrosine kinases. This inhibits Fms and Trk-mediated signaling transduction pathways that are upregulated in certain cancer cell types. This may eventually halt tumor cell proliferation in Fms and TrkA, TrkB, and/or TrkC-overexpressing tumor cells. Fms and TrkA, TrkB, and TrkC are receptor tyrosine kinases that are upregulated or mutated in a variety of tumors and promote tumor cell proliferation and survival. 